and two experimental papers on rapidly compressed plasmas. There is the usual impressive list of editors, and, as befits the organ of an international agency, abstracts are provided in four langurges, English, French, Spanish and Russian.

\section{Ilfracombe and District Ordnance Survey Map}

The Ordnance Survey Department has published a map at the scale of $2 \frac{1}{2}$ in. to the mile showing the North Devon coast from Saunton Sands to Combe Martin and extending nearly ten miles inland; Lundy Island is shown as an inset (Map of Ilfracombe and District. Sheet 856. Scale: 1:25,000, about $2 \frac{1}{2}$ inches to one mile. Chessington, Surrey : Ordnance Survey, 1961. Paper, 6s. 6d. net). Two new features have been introduced in this publication. The sheet size has been increased from the $10-\mathrm{km}$. square, at present used for Ordnance Survey maps at this scale, to $20 \mathrm{~km}$. east to west by $15 \mathrm{~km}$. north to south (roughly $12 \frac{1}{2}$ miles by $9 \frac{1}{2}$ miles). In addition, to keep the price as low as possible, the cardboard cover normally used for the folded style maps has boen discarded and the cover design has been printed as an integral part of the map. Covering as it does a very popular holiday and walking area, it is questionable whether the last-mentioned innovations have not, in fact, jeopardized the durability of the map, which is likely to have to stand up to some rough treatment.

\section{Science Progress}

A valuable review of the giberellins by $P$. W. Brian, of the Akers Research Laboratories, Imperial Chemical Industries, Ltd., in the latest issue of Science Progress $(49$, No. $193 ; 1961)$ is accompanied by two other articles which should be of considerable interest to those wishing to extend their knowledge of genetics. Dr. G. H. Beale, of the Department of Animal Genetics, University of Edinburgh, describes recent work on the mechanics of cytoplasmic inheritance, while Dr. Gordon Haskell, of the Genetics Department, Scottish Agricultural Institute, reviews scientific advances in the past decade which are associated with the life-history and cyto-genetics of the genus Rubus. The journal also contains the usual sections describing recent developments in various branches of natural science, and many authoritative book reviews.

\section{A Large Red-Shift}

NeBUlar red-shifts up to one-fifth of the velocity of light have been reached by spectroscopic investigations. The absorption features in the spectra of even fainter and more distant galaxies are veiled by the night-sky spectrum. Emission lines remain visible for much fainter galaxies than absorption lines, and the detection of galaxies with strong emission lines would therefore permit spectroscopic determination of very large red-shifts. The investi gation of radio sources offers a promising way of finding distant galaxies with emission lines; many of the strongest radio sources have been identified with such galaxies. Among the known radio sources one has now been identified with a galaxy of apparent magnitude 21, which appears to be the brightest member of a cluster of galaxies, and which has a spectrum showing a strong emission line at $\lambda 5448 \AA$. The emission line is almost certrinly the forbidden doublet of ionized oxygan, the laboratory wavelength of which is $3728 \AA$., and the large red-shift corresponds to a velocity of 0.46 times the velocity of light (R. Minkowski, Astrophys. J., 132, 909; 1960). W. A. Baum has used photo-electric photometry to determine a red-shift of 0.44 times the velocity of light for two fainter galaxies of the cluster. There is thus every reason to believe that the first galaxy is, indeed, a real member of the cluster of galaxies. These results establish the possibility of reaching red-shifts which are large enough to permit discrimination between different cosmologicel theories.

\section{Scottish Field Studies Association}

RECENTLY the programme for the Scottish Field Studies Association has become available and shows a welcome expansion in the scope of its courses, of which seventeen are now being offered. The majority of the botanical courses are once more centred on the Garth Field Centre. However, other courses are being organized at : the Isle of Raasay and the Isle of Great Cumbræ (marine biology); the Isle of Arran and North Ballachulish (geology); Beinn Eighe, the Isle of Arran and Strathpeffer (zoology). Two geographical field studies are being arranged from the Garth Field Centre and in the Strathpeffer region. Fees for the courses, which in each case last a week, vary from $£ 7$ to $£ 11$ s. Further information can be obtained from the Scottish Field Studies Association, 179 West Regent Street, Glasgow, C.2.

\section{Institute of Metals}

THE spring meeting and annual general meeting of the Institute of Metals are to be held at Church House, Great Smith Street, London, S.W.1, during March 21-23. The annual general meeting will be held on the morning of March 21. On each occasion the programme is divided into two sections, $A$ and $B$, which will run concurrently in the Hoare Memorial Hall and the Convocation Hall, as follows : March 21 (A) compatibility problems in gas-cooled reactors, (B) aluminium alloys (Prof. M. Polanyi will be giving the May Lecture, entitled "Science: Academic and Industrial", in the evening) ; March 22 ( $A$ ) copper alloys and $\mathrm{X}$-ray fluorescence analysis, $(B)$ the contribution of constitutional research to general metallurgical problems; March $23(A)$ extrusion, $(B)$ segregation to grain boundaries. Further information can be obtained from the Secretary, Institute of Metals, 17 Belgrave Square, London, S.W.1.

\section{International Congress on Metallic Corrosion}

THe first International Congress on Metallic Corrosion is to be held at the Imperial College of Science and Technology, London, S.W.7, during April 10-15. The programme has been divided into fifteen sessions which include such topics as effects of corrosion, corrosion inhibitors, corrosion protection, high-temperature oxidation, corrosion fatigue, ete. It will also include four plenary lectures : "Chemical and Electrochemical Behaviour of Metals at Passivation Ranges", by Prof. Y. M. Kolotyrkin ; "Radiotracers as applied to the Study of Metallic Corrosion", by Prof. P. Lacombe; "The Advancing Frontiers of Corrosion Science", by Prof. H. H. Uhlig ; "Factors deciding between Active Corrosion and Protective Film Formation", by Dr. U. R. Evans. Further information can be obtained from the Honorary Secretary, The First International Congress on Metallic Corrosion, 14 Belgrave Square, London, S.W.1. 